\title{
Polipropilen esaslı meltblown nonwoven kumaşların üretim koşullarının değiştirilmesi ile bazı özelliklerinin incelenmesi
}

\author{
Investigation of some properties of polypropylene based meltblown nonwoven fabrics by \\ changing the production conditions
}

\author{
Utkay DÖNMEZ*1,a, Murathan SEVİM ${ }^{1, b}$, Hacer NOZOĞLU ${ }^{1, c}$, Cuma Yaşar NACAR ${ }^{1, d}$, Doğan \\ AKGÜL ${ }^{1, e}$, Abdulkadir ERSOY ${ }^{1, \mathrm{f}}$ \\ ${ }^{1}$ Teknomelt Teknik Mensucat San. ve Tic. A.Ş. OSB 1. Cad No:12 Onikişubat,46100, K.Maraş
}

• Geliş tarihi / Received: 12.02.2020 • Düzeltilerek geliş tarihi / Received in revised form: $25.11 .2020 \quad$ • Kabul tarihi / Accepted: 30.12 .2020

\section{$\ddot{O} z$}

Polipropilen meltblown kumaşlar, sahip oldukları özellikleri sayesinde sorbent, filtrasyon, hijyen ve diğer sektörlerdeki kullanımları her geçen gün artmaktadır. Meltblown üretimdeki proses çeşitliliğinin getirdiği avantajlar sayesinde gramaj, kalınlık, mukavemet, hava geçirgenliği, yağ emicilik gibi fiziksel özelliklerde farklı değerler elde edilebilmektedir. Aynı gramajdaki meltblown kumaşlar, farklı kalınlık veya farklı mukavemet değerlerinde üretilebilmektedir. Bu durum, meltblown kumaşlara büyük bir kullanım avantajı sağlamaktadır. Bu çalışmada, $29 \mathrm{~m} / \mathrm{dk}$ belt hızı ve $29 \mathrm{rpm}$ pompa devrinde üretilen meltblown kumaşların fiziksel özelliklerinin, blower sıcak hava devri, belt-kalıp mesafesi, blower sıcaklığı, polimer erime sıcaklığı ve belt hava emiş devri gibi meltblown üretim parametrelerine bağlı olarak nasıl değiştiği izlenmiştir. Meltblown kumaşların mukavemet, hava geçirgenliği, yağ absorplama ve filtrasyon verimliliği testleri uygulanmış ve sonuçları analiz edilmiştir. Üretim parametrelerinde gerçekleştirilen değişimler, meltblown kumaşların performanslarını etkilemiştir. Yağ emilim değeri \%1115-1451 aralığında, hava geçirgenlik değeri 417-668 $1 / \mathrm{m} 2 / \mathrm{sa}$ aralı̆̆ında ve filtrasyon verimliliği değeri ise \%20.11-\%30.63 aralı̆̆ında tespit edilmiştir. Test sonuçlarına göre en iyi performans gösteren kumaşların üretim parametreleri, ilgili kullanım alanları için referans olarak önerilmiştir.

Anahtar kelimeler: Meltblown, Performans testleri, Üretim parametreleri

\begin{abstract}
Polypropylene meltblown fabrics, thanks to their properties, their use in sorbent, filtration, hygiene and other sectors are increasing day by day. Thanks to the advantages of the process variety in meltblown production, different values can be obtained in physical properties such as weight, thickness, strength, air permeability and oil absorption. Meltblown fabrics of the same weight can be produced with different thickness or different strength values. This gives a great advantage to meltblown fabrics. In this study, it was observed how the physical properties of meltblown fabric produced at $29 \mathrm{~m} / \mathrm{min}$ belt speed and 29 rpm pump speed change depending on meltblown production parameters such as blower hot air, beltmold distance, blower temperature, polymer melting temperature and belt air suction. Strength, air permeability, oil absorption and filtration efficiency tests were applied to the Meltblown fabrics and the results were analyzed. Changes in production parameters affected the performance of meltblown fabrics. Oil absorption value was determined between $1115-1451 \%$, air permeability between $417-668 \mathrm{l} / \mathrm{m} 2 / \mathrm{hr}$, and filtration efficiency value between $20.11 \%-30.63 \%$. The production parameters of the best performing fabrics according to the test results are proposed as reference for their respective usage areas.
\end{abstract}

Keywords: Meltblown, Performance tests, Production parameters

\footnotetext{
*a Utkay DÖNMEZ; utilers@gmail.com, Tel: (0344) 25791 19, orcid.org/0000-0003-3847-4773

${ }^{\mathrm{b}}$ orcid.org/0000-0002-8269-4039 $\quad{ }^{\mathrm{c}}$ orcid.org/0000-0001-7731-0366 $\quad$ orcid.org/0000-0002-6899-3665

e orcid.org/0000-0003-1747-2509 


\section{Giriş}

Polipropilen (PP), termoplastik polimerlerin kullanımının uygun olduğu üretim yöntemlerinde kullanılan en yaygın polimerdir. Düşük maliyetli olmasının yanı sıra bertaraf edilebilmesi (termik santrallerde yakılabilmesi) veya tekrar kullanılabilir olması PP polimerini, nonwoven sektöründe tercih edilen ve en yaygın kullanılan polimer haline getirmiştir (Zhang vd., 2002; Dutton, 2008; Duran ve Perinçek, 2010; Dönmez vd., 2019a).

Meltblown (eriyik üfleme) yöntemi, eriyik haldeki polimerin, sıcak ve yüksek hava basıncına maruz bırakılması ile oluşan liflerin bir araya getirilmesi ile elde edilen bir nonwoven üretim yöntemidir. Kumaş üretiminin çok kısa sürmesi, masterbatch veya sıvı kimyasallar ile kumaş özelliklerinin geliştirilebilmesi gibi avantajları sebebiyle meltblown kumaş üretim yöntemi tercih edilen bir yöntem olmuştur (Subbiah vd., 2005; Dönmez vd., 2019a). Günümüzde meltblown yöntemi mikrolif üretiminde yaygın olarak kullanılmaktadır. Meltblown kumaşlar, geniş yüzey alanı, yumuşaklık, gözenekli ve mikro yapılarından kaynaklanan özellikleri nedeniyle benzersiz malzemelerdir (Mukhopadhyay, 2002; Russell, 2007; Hegde ve Bhat, 2010). Bu kumaşlar filtrasyon, akustik yalıtım, hijyen, sorbent ve kompozit ürünlerde yaygın olarak kullanılmaktadır (Demiröz Gün vd., 2011; Duran ve Duran, 2013). Üretilen liflerin mukavemetleri düşüktür. Lif çapları, lif boyunca ve lifler arasında büyük değişiklikler göstermektedir (Hassan vd., 2013; Lalagiri vd., 2013; Duran vd., 2013; Dönmez vd; 2019a).

Meltblown üretim yönteminde öncelikle polimer ekstruderde eritilmekte, filtrasyon adımlarından geçmekte ve sonra bir pompa ile lif çekim başlıklarına gelmektedir. Burada düzeden püskürtülen erimiş polimer direkt olarak düze ağzında yüksek hızdaki sıcak havaya maruz kalmaktadır (Horrocks ve Anand, 2000). Bu şekilde lif hava karışımı oluşmaktadır. Erime şartlarına, lif şekline ve sıcaklığa bağlı olarak lif çekimi 6000-30000 $\mathrm{m} / \mathrm{dk}$ hızda hava ile gerçekleştirilmektedir. Yüksek sıcaklıkta lifleri çekmek için hava sıcaklığı liflerin erime sıcaklığına göre ayarlanır (Albrecht vd., 2003). Daha sonraki aşamada soğuk hava uygulanır. Soğuk hava sıcak hava ile karışır ve polimer katılaşır. İncelen lifler en son aşama olarak alt tarafta bulunan toplayıcı üzerine düşerek nonwoven oluştururlar (Albrecht vd., 2003; Mukhopadhyay ve Ramakrishnan, 2008). Meltblown yönteminin şematik olarak görüntüsü Şekil 1'de verilmiştir (Srinivas vd., 2005).

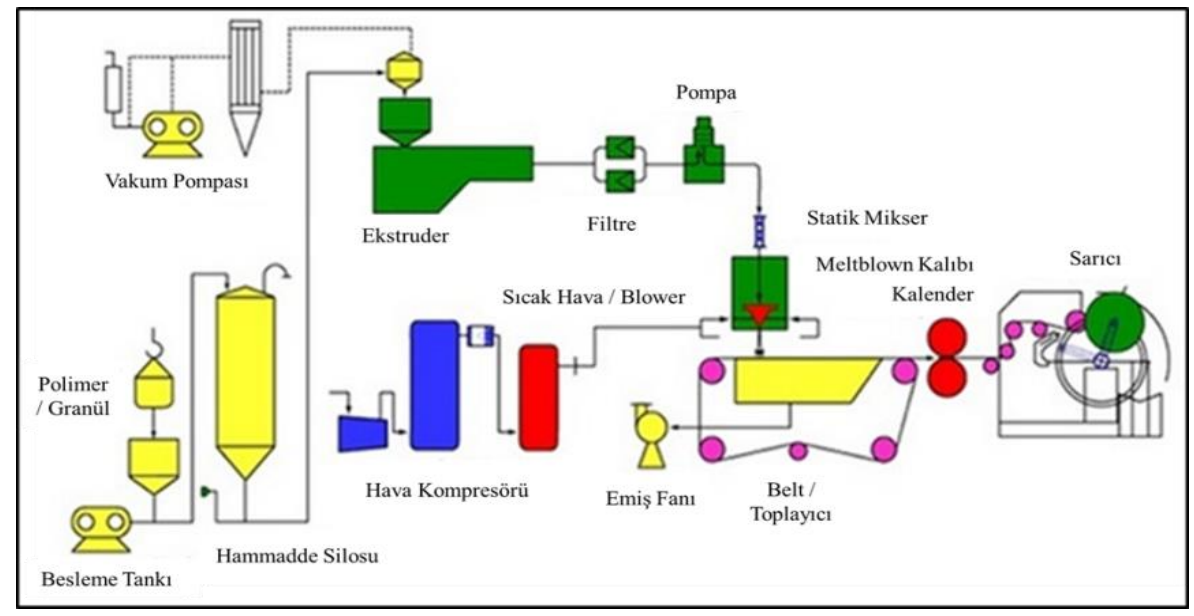

Şekil 1. Meltblown Kumaş Üretim Makinesi Şematik Gösterimi (Srinivas vd., 2005)

Eriyik üfleme yöntemi ile üretilen meltblown kumaşların performansına blower isısı ve blower hava hızı, kalıp fiziksel özellikleri ve kalıp sicaklığ1, polimer erime sıcaklığ devri, belt- kalıp arası mesafe parametreleri etki etmektedir (Dutton 2008; Bin vd., 2016; Xiao vd., 2019; Dönmez vd., 2019b).
Kalıptan çıkan polimer eriyiği, toplayıcıya ulaşana kadar blower havasının etkisiyle çekime uğrar ve en zayıf anında koparak lif oluşumunu gerçekleştirir. Burada life uygulanan kuvvet, blower tarafindan oluşturulan havanın hızı ve havanın sıcaklık değeridir. Polimere uygulanan kuvvet için birim alana uygulanan kuvvet ifadesi ile alanda biriken polimer miktarı önem kazanmaktadır (Ward, 2001; Albrecht vd., 2003; 
Bhat vd., 2009) Polimer miktarı az ise polimere uygulana kuvvet ters orantılı şekilde artacaktır, polimer miktarı çok ise birim polimere uygulanacak kuvvet miktarı azalacaktır (Ward, 2001; Bhat vd., 2009; Han vd., 2013; Wei, 2018).

Blower havasının sıcaklığı ise polimer eriyiğine uygulanan kuvvete doğrudan etkilidir. Eriyik polimere açısal bir kuvvet uygulayarak akışkan haldeki polimeri daha soğuk ortama sürükleyen blower havası, polimer eriyiğine çekim uygulayarak kalıptan uzaklaştırmaktadır. $\mathrm{Bu}$ aşamada lif oluşumu gerçekleşmektedir. Kalıptan sonraki süreçte blower havası ile liflere çekim işlemi uygulanarak elde edilen lifin ve kumaşın fiziksel özelliklerinde değişiklikler oluşturulabilmektedir (Ellison vd., 2007; Dutton, 2008; Uppal vd., 2013, Han vd., 2013).

Meltblown kumaşlar, hava filtreleme uygulamalarında yaygın olarak kullanılmaktadır. Membranlı yapilarda destek malzemesi olarak da meltblown kumaşlar kullanılabilmektedir. Bahsedilen fonksiyonların yanı sıra, düşük maliyetleri onları birçok uygulama için cazip kılmaktadır (Doğan, 2006). Tek kullanımlık ürünlerin tüketimindeki artış, nüfustaki artış, daha yüksek performans / maliyet oranı gibi sebepler, dokuma olmayan filtreleri, cazip hale getirmiştir (Kaynak ve Değirmenci, 2010). Bir filtrenin performansını etkileyen yapısal parametreler lif çap1 ve geometrisi, yüzey alan1, gözeneklilik, yüzey yapısı, kumaş kalınlığ 1 ve yoğunluğu, birim alan başına hacim ve kütledir (Duran vd., 2013).

$\mathrm{Bu}$ çalışmada meltblown üretim tekniğinde kumaş yapısı üzerine etkili olan kalıp-belt mesafe, blower devri, blower hava sicaklığı, polimer erime sicaklığı, belt (sunction) hava emiş devri parametreleri incelenmiştir. Diğer üretim parametreleri sabit tutulmuştur.

\section{Materyal ve metot}

\subsection{Materyal}

Meltblown kumaş üretimi için MFI değeri 1200 $\mathrm{g} / 10 \mathrm{dk}$ olan polipropilen (PP) kullanılmıştır.

\subsection{Metot}

\subsubsection{Polipropilen meltblown nonwoven üretimi}

Meltblown nonwoven kumaş üretimleri, Teknomelt Teknik Mensucat San. Ve Tic. A.Ş. firmasında gerçekleştirilmiştir. Meltblown kumaşlar $160 \mathrm{~cm}$ eninde ve $30 \mathrm{~g} / \mathrm{m}^{2}$ olarak üretilmiştir. PP esaslı meltblown nonwoven üretimleri Tablo 1'de verilmişsir.

Tablo 1. Meltblown nonwoven üretim parametreleri

\begin{tabular}{|c|c|c|c|c|c|c|c|c|}
\hline Numuneler & $\begin{array}{l}\text { Belt-Kalıp } \\
\text { Mesafe (cm) }\end{array}$ & $\begin{array}{c}\text { Blower Sicak } \\
\text { Hava Devri } \\
\text { (rpm) }\end{array}$ & $\begin{array}{c}\text { Blower } \\
\text { Hava } \\
\text { Sicaklığ } \\
\left({ }^{\circ} \mathrm{C}\right)\end{array}$ & $\begin{array}{c}\text { Polimer } \\
\text { Erime } \\
\text { Sicaklığı } \\
\left({ }^{\circ} \mathrm{C}\right)\end{array}$ & $\begin{array}{c}\text { Belt Hava } \\
\text { Emiş Devri } \\
(\text { rpm })\end{array}$ & $\begin{array}{c}\text { Kalıp } \\
\text { Sicaklığ } \\
\left({ }^{\circ} \mathbf{C}\right)\end{array}$ & $\begin{array}{c}\text { Polimer Besleme } \\
\text { Pompa Devri } \\
\text { (rpm) }\end{array}$ & $\begin{array}{c}\text { Belt Hızı } \\
(\mathbf{m} / \mathbf{d k})\end{array}$ \\
\hline MBTAS-1 & 40 & \multirow{3}{*}{1750} & \multirow{9}{*}{275} & \multirow{9}{*}{260} & \multirow{9}{*}{300} & \multirow{18}{*}{265} & \multirow{18}{*}{23} & \multirow{18}{*}{29} \\
\hline MBTAS-2 & 45 & & & & & & & \\
\hline MBTAS-3 & 50 & & & & & & & \\
\hline \begin{tabular}{|l|} 
MBTAS-4 \\
\end{tabular} & 40 & \multirow{3}{*}{1800} & & & & & & \\
\hline MBTAS-5 & 45 & & & & & & & \\
\hline MBTAS-6 & 50 & & & & & & & \\
\hline MBTAS-7 & 40 & \multirow{3}{*}{1850} & & & & & & \\
\hline MBTAS-8 & 45 & & & & & & & \\
\hline MBTAS-9 & 50 & & & & & & & \\
\hline MBTAS-10 & 40 & \multirow{3}{*}{1750} & \multirow{9}{*}{285} & \multirow{9}{*}{265} & \multirow{9}{*}{400} & & & \\
\hline MBTAS-11 & 45 & & & & & & & \\
\hline MBTAS-12 & 50 & & & & & & & \\
\hline MBTAS-13 & 40 & \multirow{3}{*}{1800} & & & & & & \\
\hline MBTAS-14 & 45 & & & & & & & \\
\hline MBTAS-15 & 50 & & & & & & & \\
\hline MBTAS-16 & 40 & \multirow{3}{*}{1850} & & & & & & \\
\hline MBTAS-17 & 45 & & & & & & & \\
\hline MBTAS-18 & 50 & & & & & & & \\
\hline
\end{tabular}




\subsubsection{Meltblown nonwoven kumaşların değerlendirme yöntemleri}

Hazırlanan meltblown kumaş numuneleri $20 \pm 2{ }^{\circ} \mathrm{C}$ sicaklıkta ve $\% 65 \pm 2$ nem oranında 24 saat süresince kondisyonlanmıştır. $\mathrm{Bu}$ süre sonunda meltblown kumaş performans parametreleri incelenmiştir.

\subsubsection{Gramaj dağılım analizi}

Üretimi gerçekleştirilen meltblown kumaşların, EDANA-NWSP 130.1.R0 (15)-Birim Alan Başına Kütle yöntemine göre gramajları hesaplanmış ve standart sapmaları incelenmiştir.

\subsubsection{Mukavemet analizi}

Nonwoven kumaşlar, makine (MD) yönü ve makine eni $(\mathrm{CD})$ yönündeki kopma dayanımı ve \%-uzama değerleri Dokusuz Yüzeylerin Kopma Dayanımı ve Uzamas1 (Strip Metodu) (EDANANWSP 110.4.R0 (15)) yöntemine göre test edilmiştir. Testler, Teknomelt Arge Merkezinde bulunan ZwickRoell $0.5 \mathrm{kN}$ cihazı ile yapılmıştır.

\subsubsection{Yă̆ ve yağ sıvılarının emiliminin analizi}

Üretimi gerçekleştirilen meltblown kumaşların EDANA-NWSP 130.1.R0 (15)-Birim Alan Başına Kütle yöntemine göre gramajları ve standart sapmaları değerleri belirlenmiştir. İlk tartımı ve yağ emdirildikten sonraki son tartımı alınan numuneler, EDANA-NWSP 010.4.R0 (15)- Yağ ve Yağ Sıvılarının Emiliminin Değerlendirilmesi yöntemine göre içlerine hapsettikleri yağ miktarları ve standart sapma değerleri denklem-1'e göre belirlenmiş̦tir. Kullanılan yağ ise $10 * 40$ olarak bilinen motor yağıdır.

$\%$ Yağ Emicilik Oranı $=\left(\frac{T 2-T 1}{T 1}\right) * 100$

\subsubsection{Hava geçirgenlik analizi}

Meltblown nonwoven kumaşların hava geçirgenlik değeri EDANA- NWSP 070.1.R0 (15) Hava Geçirgenliği test standardına göre belirlenecektir. Standarda göre, $20 \mathrm{~cm}^{2}$ numune tutucu ve $196 \mathrm{~Pa}$ basınç altındaki hava geçiş miktarını tespit edilmektedir. Her numuneden 10 adet ölçüm yapılmış ve ortalamaları alınarak değerlendirilmiştir. Ölçümler Pro-White Air TestII marka hava geçirgenliği cihazında gerçekleştirilmiştir.

\subsubsection{Filtrasyon verimliliği analizi}

Meltblown kumaşlar filtre sektöründe özellikle ön filtre, toz torbası, yüz maskesi gibi endüstriyel uygulamalarda kullanılmaktadır. Sektörde farklı kullanım alanları için farklı standartlar uygulanmaktadır. Bu çalışmada, TSI 8130a marka test cihazında ve EN $149+$ A1- Solunumla İlgili Koruyucu Cihazlar -Parçacıklara Karşı Koruma Amaçlı Filtreli Yarım Maskeler- Özellikler, Deneyler Ve İşaretleme standardına göre $0.3 \mu \mathrm{m}$ $\mathrm{NaCl}$ aeroseol partikül, 32 1/dk hava akış hızında tek kat formunda test edilmiştir.

\section{Bulgular ve tartışma}

\subsection{Gramaj dağımı test sonuçları}

Meltblown nonwoven kumaşlar için belirtilen üretim parametrelerinden belt hızı ile pompa devri arasındaki korelasyon meltblown kumaşın gramajı ayarlanmasında en etkin role sahiptir. Meltblown nonwoven kumaşlar gramaj ölçümleri, $160 \mathrm{~cm}$ kumaş eni boyunca 10'ar adet numune alınarak ölçümler gerçekleştirilmiştir. Tablo 2'de numunelere ait gramaj ölçümleri ve standart sapmalarına ait veriler sunulmuştur.

Tablo 2. $30 \mathrm{~g} / \mathrm{m}^{2}$ olarak çalışan kumaşların gramaj ölçümlerine ait test sonuçları

\begin{tabular}{lccc}
\hline \multirow{2}{*}{ Numuneler } & \multicolumn{3}{c}{ Gramaj $\left(\mathbf{g} / \mathbf{m}^{\mathbf{2}}\right)$} \\
\cline { 2 - 4 } & Ortalama & Standart Sapma & $\mathbf{\% C V}$ \\
\hline MBTAS-1 & 32.5 & 1.84 & 5.66 \\
MBTAS-2 & 32.6 & 2.37 & 7.26 \\
MBTAS-3 & 32.1 & 2.02 & 6.31 \\
MBTAS-4 & 31.9 & 2.47 & 7.74 \\
MBTAS-5 & 31.4 & 2.95 & 9.40 \\
MBTAS-6 & 31.3 & 2.95 & 9.41 \\
MBTAS-7 & 32.5 & 2.27 & 6.99 \\
MBTAS-8 & 31.1 & 2.69 & 8.63 \\
MBTAS-9 & 31.6 & 2.22 & 7.03 \\
MBTAS-10 & 31.9 & 2.42 & 7.60 \\
MBTAS-11 & 32.2 & 2.9 & 9.00 \\
MBTAS-12 & 34.1 & 1.2 & 3.51 \\
MBTAS-13 & 31.7 & 2.31 & 7.29 \\
MBTAS-14 & 32.3 & 1.77 & 5.47 \\
MBTAS-15 & 31.0 & 2.21 & 7.13 \\
MBTAS-16 & 32.2 & 3.19 & 9.91 \\
MBTAS-17 & 31.8 & 1.99 & 6.25 \\
MBTAS-18 & 32.1 & 3.0 & 9.34 \\
\hline
\end{tabular}

Meltblown kumaş üretimi $30 \pm 2 \mathrm{~g} / \mathrm{m}^{2}$ olarak ayarlanmıştır. Ancak bazı numunelerin limitler dışına çıktığı görülmektedir. Bu durumda çalışılan parametrelerde gramaj dağılımını olumsuz yönde etkilediği görülmüştür. Söz konusu numunelerde, kumaşın tam en boyunca aynı performansı gösteremeyeceğini anlaşılmaktadır. 


\subsection{Mukavemet (kopma-\%uzama dayanımı) test sonuçları}

Meltblown nonwoven kumaşların $\mathrm{MD}$ ve $\mathrm{CD}$ yönünde, kopma dayanımı (M) ve \%-uzama (U) değerleri incelenmiştir. Numuneler, $5 \mathrm{~cm} * 20 \mathrm{~cm}$ ebatlarında hazırlanmış ve 3'er tekrarlı olmak üzere kumaşların 4 farklı bölgesinden alınarak ölçülmüş ve ortalamaları değerlendirilmiştir. Meltblown numunelerin mukavemet değerlerine ait veriler Tablo 3 'te verilmiştir.

Tablo 3. Meltblown nonwoven kumaşlara ait kopma-\% uzama değerleri

\begin{tabular}{ccccc}
\hline & \multicolumn{3}{c}{ Kopma-\% Uzama Değerleri (MD- } \\
\cline { 2 - 5 } Numuneler & $\begin{array}{c}\text { M-MDort } \\
\text { (N/5 cm) }\end{array}$ & $\begin{array}{c}\text { M-CD } \mathbf{~ o r t ~} \\
\text { (N/5 cm) }\end{array}$ & $\begin{array}{c}\text { U-MD ort } \\
(\mathbf{\%})\end{array}$ & $\begin{array}{c}\text { U-CD } \\
(\boldsymbol{\%})\end{array}$ \\
\hline MBTAS-1 & 7.0 & 0 & 2.0 & 0 \\
MBTAS-2 & 7.5 & 0 & 1.5 & 0 \\
MBTAS-3 & 6.1 & 5.5 & 1.0 & 4.5 \\
MBTAS-4 & 7.6 & 5.9 & 3.0 & 7.0 \\
MBTAS-5 & 6.6 & 5.5 & 4.5 & 2.5 \\
MBTAS-6 & 6.1 & 5.1 & 3.0 & 0.5 \\
MBTAS-7 & 6.8 & 5.6 & 2.0 & 3.0 \\
MBTAS-8 & 7.0 & 5.7 & 2.5 & 5.0 \\
MBTAS-9 & 7.0 & 5.2 & 3.0 & 1.0 \\
MBTAS-10 & 9.1 & 5.9 & 3.0 & 4.5 \\
MBTAS-11 & 7.7 & 5.7 & 4.0 & 4.5 \\
MBTAS-12 & 7.3 & 6.1 & 3.5 & 7.0 \\
MBTAS-13 & 10.1 & 5.9 & 3.0 & 3.5 \\
MBTAS-14 & 9.1 & 5.8 & 3.0 & 4.5 \\
MBTAS-15 & 8.4 & 6 & 6.0 & 7.5 \\
MBTAS-16 & 8.2 & 5.2 & 2.5 & 1.7 \\
MBTAS-17 & 8.8 & 5.5 & 4.0 & 3.0 \\
MBTAS-18 & 7.9 & 5.6 & 2.0 & 2.5 \\
\hline
\end{tabular}

Ölçümlerin yapılması sırasında bazı numunelerin ölçümlerinin yapılamadığı görülmüştür. $\mathrm{Bu}$ meltblown kumaşların, mukavemet testlerinin gerçekleştirilmesi sırasında uygulanan tansiyona dayanamayarak koptuğu gözlemlenmiştir. $\mathrm{Bu}$ numunelerin mukavemet değerleri sifir olarak kayıtlara geçmiştir.

Meltblown nonwoven kumaş üretiminde önemli parametrelerden olan blower sicak hava devri parametresi ve kalip-belt mesafesine ait değişkenlerin kopma dayanımı değerleri üzerindeki etkisi Şekil 2'de verilmiştir.

Şekil 2 incelendiğinde, MD yönündeki en iyi değeri MBTAS-13 numunesi, en kötü değeri ise MBTAS-3/MBTAS-6 kodlu numuneler vermiştir. CD yönünde ise en iyi değeri MBTAS-12, en kötü değeri ise MBTAS-6 kodlu numuneler vermiştir.

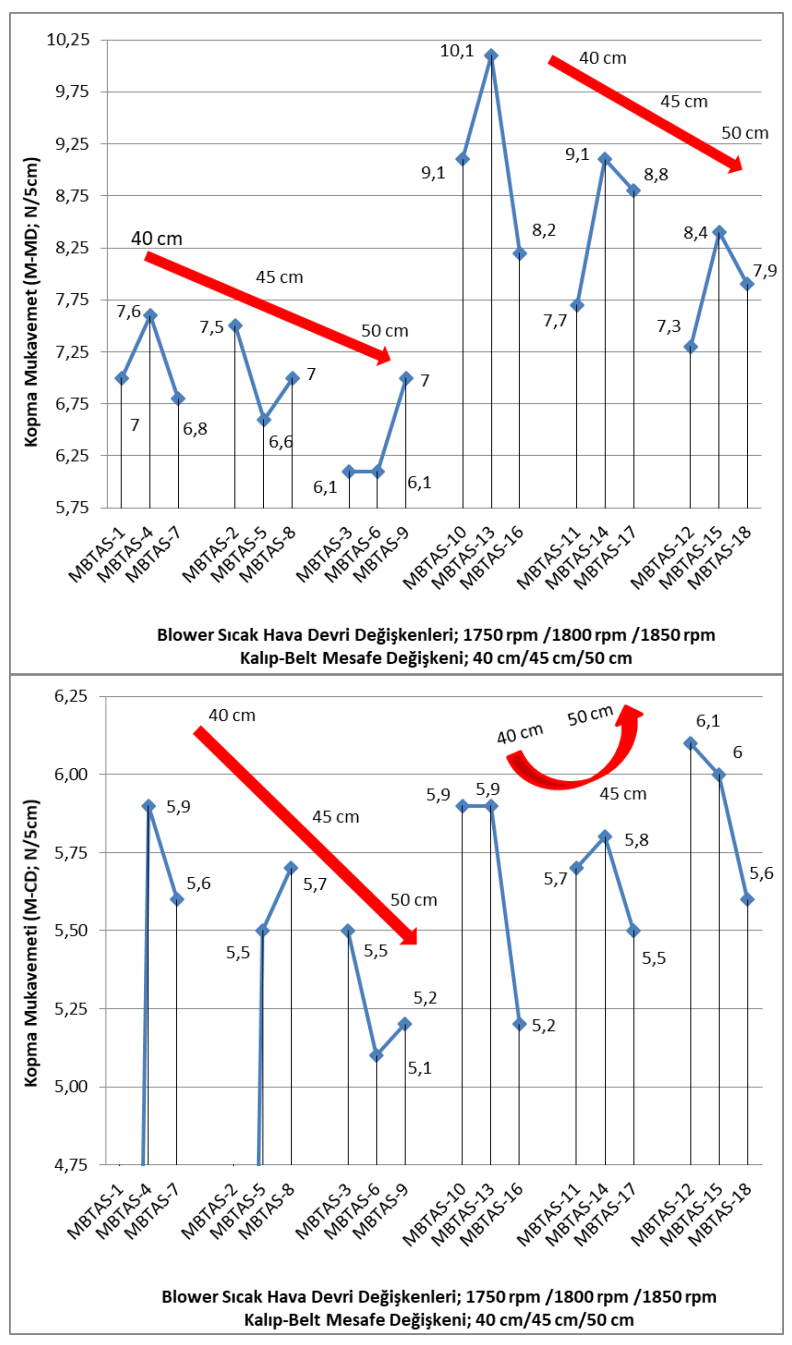

Şekil 2. Meltblown kumaşların $\mathrm{MD} / \mathrm{CD}$ yönü kopma dayanımları. Değişkenler; blower sıcak hava devri ve belt-kalıp mesafesi.

Blower hava sıcaklığı, polimer erime sıcaklığı, belt hava emiş devri ve belt-kalıp mesafesi parametrelerinin sabit tutulduğu numune gruplarında (örneğin MBTAS-1, MBTAS-4, MBTAS-7 ya da MBTAS-10, MBTAS-13, MBTAS-16 gibi), blower sıcak hava devri arttıkça, MD yönü kopma dayanımı düzenli bir şekilde hareket etmediği, istatistiki bir veri elde edilemediği görülmüştür. İlk grubunda, mukavemet değeri öncelikle artış göstermiş, daha sonra tekrar düşüş sergilemiştir. Diğer gruplarda ise daha farklı tepkiler göstermiştir. Blower sıcak hava devri arttırıldığında $\mathrm{CD}$ yönü kopma dayanımı değerlerinde de benzer bir durum tespit edilmiştir.

Blower hava sıcaklığı $275{ }^{\circ} \mathrm{C}$, polimer erime sicaklığ $260{ }^{\circ} \mathrm{C}$ ve belt hava emiş devri $300 \mathrm{rpm}$ olan MBTAS 1-9 numune grubunda, belt-kalıp mesafesi arttıkça CD yönü kopma dayanımı düşerken MBTAS 10-18 numune grubunda ise kopma dayanımı değerleri önce düşmüş sonra artış 
göstermiştir. Belt-kalıp mesafesi değeri arttırıldığında ise, MD yönü kopma dayanımı değerlerinde düşüş tespit edilmiş̧ir.

Blower sicak hava parametresi ve kalip-belt mesafesine ait değişkenlerin \%-uzama değerleri üzerindeki etkisi Şekil 3'de verilmiştir.

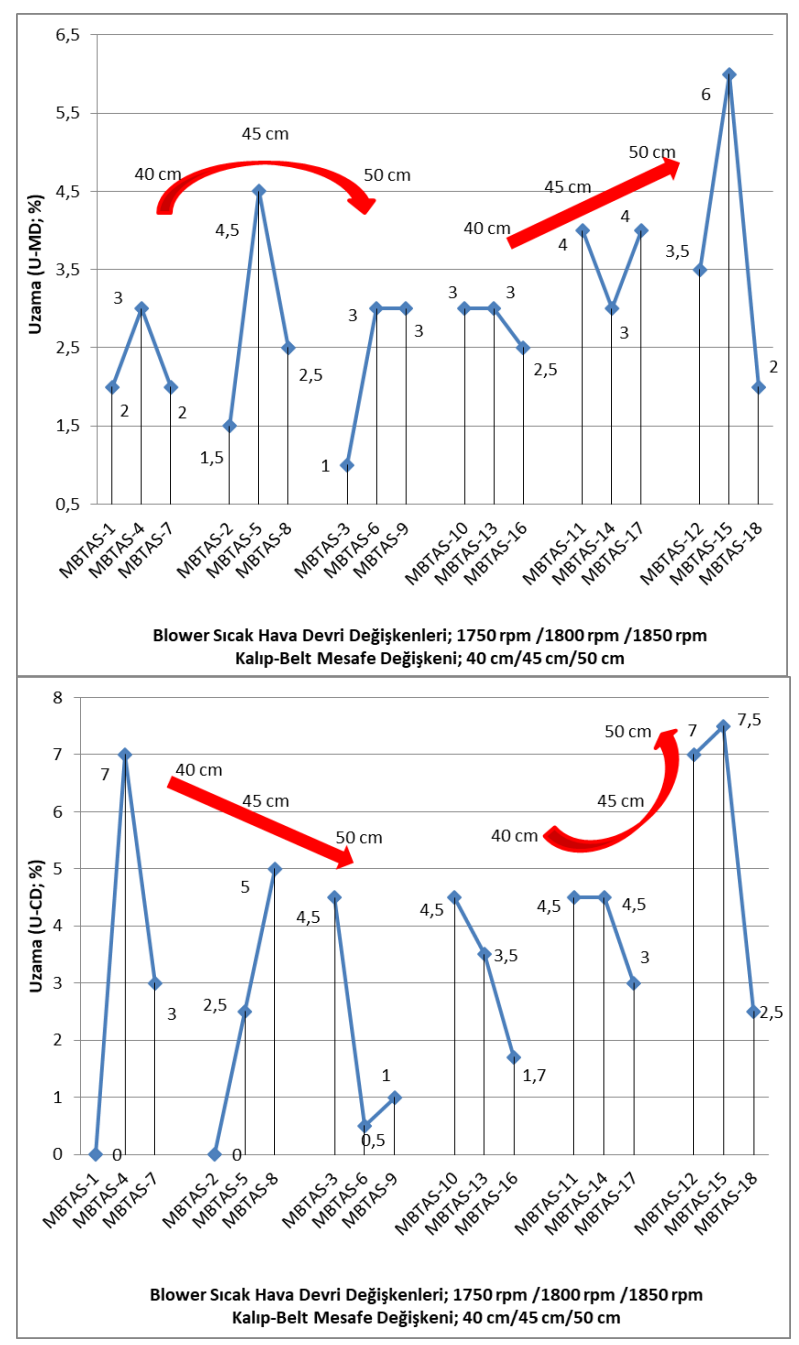

Şekil 3. Meltblown kumaşların MD/CD yönü \%Uzama değerleri. Değişkenler; blower sıcak hava devri ve belt-kalıp mesafesi.

MD yönü en iyi \%-uzama değerini MBTAS-15, en kötü \%-uzama değeri MBTAS-3 numunesi, CD yönü en iyi \%-uzama değeri MBTAS-15 kodlu numunelerde görülmüştür. Blower sicak hava devri artışının \%-uzama değerleri üzerinde belirgin bir etkisinin olmadığı görülmüştür. Numune gruplarında artış-azalış, azalış-artış ve diğer varyasyonlar tespit edilmiş ve bu durumda istatistiki bir veri okunamamıștır. Bu durum hem MD yönü hem $C D$ yönünde benzerlik göstermiştir.

Belt-kalıp mesafesi arttıkça MBTAS 1-9 numune grubunda MD yönü \%-uzama değerleri öncelikle artış göstermiş sonrasında yine düşüş göstermiştir.
MBTAS 10-18 numune grubunda ise \%-uzama değerlerinde artış olduğu görülmüştür. $\mathrm{CD}$ yönü $\%$-uzama değerleri ise MBTAS 1-9 numune grubunda düşüş göstermiştir. MBTAS 10-18 numune grubunda ise \%-uzama değeri öncelikle düşmüş daha sonra artış göstermiştir.

\subsection{Yă̆ ve yă̆ sıvılarının emilimi test sonuçları}

PP meltblown nonwoven kumaşlar, yağ emici özelliği sayesinde sorbent sektöründe aktif olarak kullanılmaktadır. Bu sebeple yă emicilik testi, meltblown kumaşlarda yağ sıvilarının emilim testi önem arz etmektedir. Yağ sıvılarının emilimi testi, kumaş $160 \mathrm{~cm}$ eni boyunca, toplamda $10 \mathrm{kez}$ tekrar ile test edilmiş ve ortalama yağ emilim (\%) değerleri Tablo 4'te verilmiştir.

Tablo 4. Meltblown nonwoven kumaşların yağ emilim oranı (\%) verileri

\begin{tabular}{lccc}
\hline \multirow{2}{*}{ Numuneler } & \multicolumn{3}{c}{ Yă Emilim Oranı (\%) } \\
\cline { 2 - 4 } & Ortalama & Standart Sapma & \% CV \\
\hline MBTAS-1 & 1227.04 & 233.36 & 19.02 \\
\hline MBTAS-2 & 1115.03 & 130.81 & 11.73 \\
\hline MBTAS-3 & 1380.22 & 95.19 & 6.90 \\
\hline MBTAS-4 & 1331.03 & 75.89 & 5.70 \\
\hline MBTAS-5 & 1392.85 & 101.31 & 7.27 \\
\hline MBTAS-6 & 1406.32 & 126.06 & 8.96 \\
\hline MBTAS-7 & 1409.27 & 63.59 & 4.51 \\
\hline MBTAS-8 & 1269.53 & 92.83 & 7.31 \\
\hline MBTAS-9 & 1340.59 & 109.22 & 8.15 \\
\hline MBTAS-10 & 1316.01 & 154.16 & 11.71 \\
\hline MBTAS-11 & 1350.36 & 126.02 & 9.33 \\
\hline MBTAS-12 & 1271.32 & 50.94 & 4.01 \\
\hline MBTAS-13 & 1287.67 & 59.28 & 4.60 \\
\hline MBTAS-14 & 1333.32 & 62.78 & 4.71 \\
\hline MBTAS-15 & 1451.06 & 144.98 & 9.99 \\
\hline MBTAS-16 & 1291.22 & 117.42 & 9.09 \\
\hline MBTAS-17 & 1278.15 & 73.31 & 5.74 \\
\hline MBTAS-18 & 1312.55 & 146.25 & 11.14 \\
\hline
\end{tabular}

Üretim parametrelerinde gerçekleştirilen değişimler ile meltblown kumaşın yağ emilim özellikleri de değişmiştir. Numuneler kendi ağırlıklarının 11-14,5 katı arası yağ emilimi göstermiştir. Standart sapma ile \%CV değeri (en iyi $\% \mathrm{CV}$ değeri 1'dir) en düşük olan numunelerde kumaşın her yerinde birbirine yakın performans gösterdiği söylenebilir.

PP meltblown kumaşlar yağ emicilik özelliklerine sahiptir. Üretim parametrelerindeki değişimler ile kumaşın fiziksel yapısı değişmekte ve bu sebeple, yağ emiş oranı da değişmektedir. Özellikle sorbent sektörü için yapılan üretimler için en uygun numune MBTAS-15 olarak tespit edilmiştir. Meltblown kumaşların değişken parametreler 
altında yağ emicilik yeteneklerine ait grafik Şekil 4 'te verilmiştir.

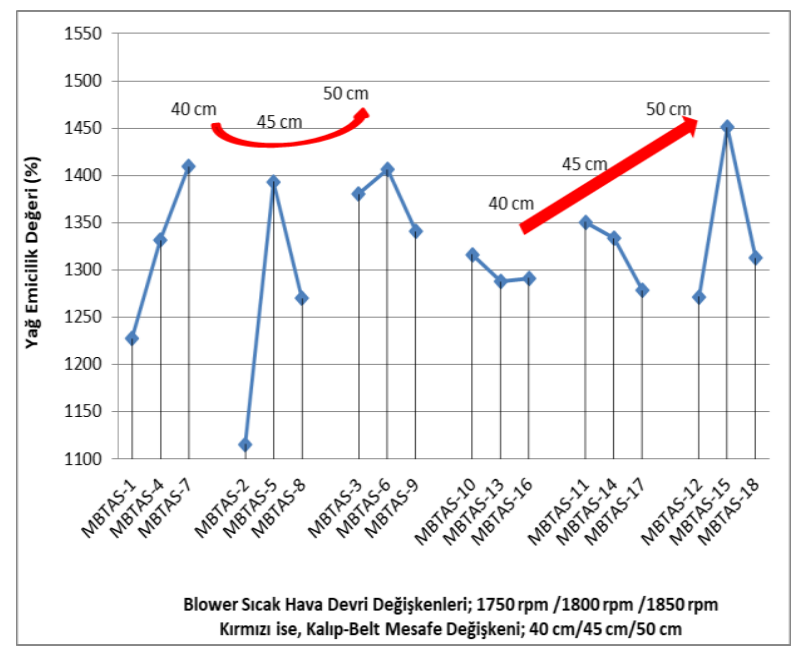

Şekil 4. Meltblown kumaşların yă emicilik oranları

Meltblown kumaşların yağ emicilik oranı kumaşın gözenek boyutu ile yakından ilgilidir. Belt-kalıp mesafesi $40 \mathrm{~cm}$ olan deneme grubunda blower sıcak hava devri artışı ile birlikte yağ emicilik oranı artmıştır. Ancak tüm deneme grubunda aynı sonuçlar tespit edilememiştir. Örneğin, diğer üç deneme grubunda yă emicilik oranı önce artış daha sonra düşüş göstermiştir. Diğer iki deneme grubunda ise blower sicak hava devrinin artışı ile yağ emicilik oranı azalış göstermiştir.

Blower hava sıcaklığ $275{ }^{\circ} \mathrm{C}$, polimer erime sicaklığ $260{ }^{\circ} \mathrm{C}$ ve belt hava emiş devri $300 \mathrm{rpm}$ olan MBTAS 1-9 numune grubunda, belt-kalıp mesafesi arttıkça, yağ emicilik oranlarında öncelikle düşüş göstermiş daha sonra tekrar artış göstermiştir. MBTAS 10-18 numune grubunda ise mesafe arttıkça, yağ emicilik oranlarında artış görülmüştür.

\subsection{Hava geçirgenliği test sonuçları}

Meltblown kumaşlar, sahip olduğu mikron (ve nadiren de olsa nano) boyuttaki lifler sayesinde hava geçirgenliği bakımından tercih edilmektedir. Özellikle de filtre ve medikal sektöründe söz konusu hava geçirgenliği değeri oldukça önem arz etmektedir. $\mathrm{Bu}$ deneysel çalışmada meltblown kumaş numuneleri tam en boyunca 10'ar adet ölçüm gerçekleştirilmiş ve ortalama değerleri Tablo 5'te verilmiştir.
Tablo 5. Meltblown numunelerin hava geçirgenliği değerleri

\begin{tabular}{lccc}
\hline \multirow{2}{*}{ Numuneler } & \multicolumn{3}{c}{ Hava Geçirgenliği $\left(\mathbf{l} / \mathbf{m}^{\mathbf{2}} / \mathbf{s a}\right)$} \\
\cline { 2 - 4 } & Ortalama & Standart Sapma & \% CV \\
\hline MBTAS-1 & 543.03 & 129.95 & 23.93 \\
MBTAS-2 & 517.06 & 84.67 & 16.38 \\
MBTAS-3 & 609.41 & 117.92 & 19.35 \\
MBTAS-4 & 538.68 & 87.62 & 16.26 \\
MBTAS-5 & 576.82 & 99.21 & 17.20 \\
MBTAS-6 & 619.86 & 123.58 & 19.94 \\
MBTAS-7 & 497.50 & 102.89 & 20.68 \\
MBTAS-8 & 516.36 & 118.24 & 22.90 \\
MBTAS-9 & 668.21 & 134.92 & 20.19 \\
MBTAS-10 & 417.16 & 90.99 & 21.81 \\
MBTAS-11 & 507.10 & 108.81 & 21.46 \\
MBTAS-12 & 532.47 & 118.07 & 22.17 \\
MBTAS-13 & 436.25 & 53.04 & 12.16 \\
MBTAS-14 & 473.07 & 58.28 & 12.32 \\
MBTAS-15 & 524.84 & 128.66 & 24.51 \\
MBTAS-16 & 435.99 & 64.31 & 14.75 \\
MBTAS-17 & 483.20 & 73.38 & 15.19 \\
MBTAS-18 & 556.70 & 110.33 & 19.82 \\
\hline
\end{tabular}

Numunelerin hava geçirgenlik değerleri 417-668 $1 / \mathrm{m}^{2} / \mathrm{sa}$ aralığında tespit edilmiştir. Parametre değişikliği ile hava geçirgenliği değerlerinin de değiştiği görülmüş̧ür. Sektörlere göre hava geçirgenliği yüksek ya da düşük istenebilmektedir. Meltblown kumaşların gözenek boyutu ve sayısındaki farklılıklar kumaşların hava geçirgenliği değerlerini de etkilemektedir. Meltblown kumaş numunelere ait hava geçirgenliği değerlerine ait grafik Şekil 5'te verilmiştir.

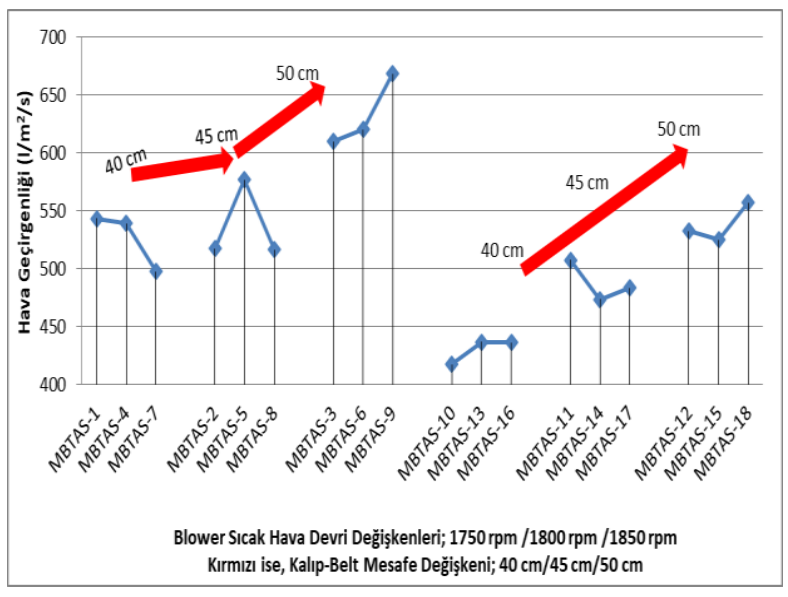

Şekil 5. Meltblown kumaşların hava geçirgenlik değerleri

En yüksek hava geçirgenliği MBTAS-9 numunesinde, en düşük hava geçirgenliği ise MBTAS-10 kodlu numunede tespit edilmiştir. Blower sıcak hava devri değerleri arttıkça hava geçirgenlik değerleri düzenli bir değişim 
göstermemiştir. MBTAS 1-4-7 ve MBTAS 10-1316 deneme gruplarında blower sicak hava devri arttıkça hava geçirgenliği azalmıştır. MBTAS 2-58 deneme grubunda ise hava geçirgenliği önce artmış daha sonra azalmıştır. Görüldüğü gibi blower sıcak hava devri arttıkça tüm gruplarda farklı sonuçlar tespit edilmiştir.

Meltblown numunelerinde belt-kalıp mesafesi arttıkça, hava geçirgenlik değerinin genel manada artış içerisinde olduğu görülmektedir. Bu durum bazı sektörler de kullanım avantajı sağlarken, bazı sektörlerde dezavantaj taşımaktadır. Hava geçirgenliği ile ilintili olabilecek bir özellik de filtrasyon verimliliğidir.

\subsection{Filtre verimliliği test sonuçları}

Meltblown kumaşlar filtre amaçlı oldukça yaygın olarak kullanılmaktadır. Filtre testleri 0.3 mikron boyutundaki $\mathrm{NaCl}$ aerosol partikül kullanılarak 32 1/dk hava hizında tek kat halinde gerçekleştirilmiştir. Meltblown kumaşların filtre testine ait veriler Tablo 6'da verilmiştir.

Tablo 6. Filtrasyon verimliliği test sonuçları

\begin{tabular}{lc}
\hline Numuneler & Filtrasyon Verimliliği (\%) \\
\hline MBTAS-1 & 20.11 \\
MBTAS-4 & 29.72 \\
MBTAS-7 & 26.98 \\
MBTAS-2 & 23.73 \\
MBTAS-5 & 21.88 \\
MBTAS- & 23.16 \\
MBTAS-3 & 23.25 \\
MBTAS-6 & 24.54 \\
MBTAS-9 & 28.88 \\
MBTAS-10 & 30.63 \\
MBTAS-13 & 30.11 \\
MBTAS-16 & 30.06 \\
MBTAS-11 & 27.13 \\
MBTAS-14 & 25.78 \\
MBTAS-17 & 24.06 \\
MBTAS-12 & 22.32 \\
MBTAS-15 & 29.53 \\
MBTAS-18 & 25.85 \\
\hline
\end{tabular}

Meltblown numunelere ait $0.3 \mu \mathrm{m} \mathrm{NaCl}$ aerosol partikülleri, 32 1/dk hava geçiş miktarı ve $5.3 \mathrm{~cm} / \mathrm{sn}$ hava hızında yapılan testlere ait veriler Şekil 6'da verilmiştir.

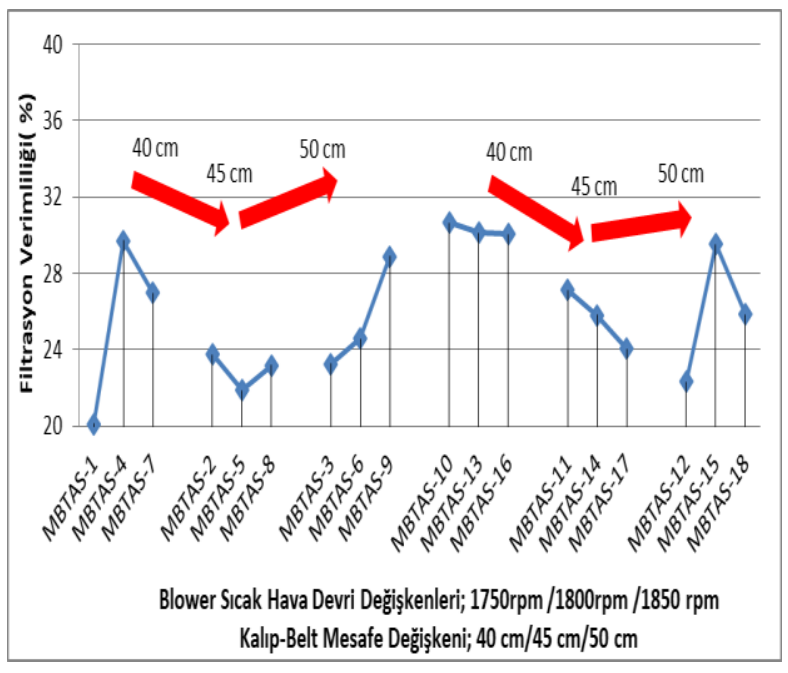

Şekil 6. Meltblown kumaşların filtre verimlilik değerleri

En yüksek filtre performansını MBTAS-10 numunesi, MBTAS-10 numunesinde en düşük filtre sonucu ise MBTAS-1 numunesinde tespit edilmiştir. Blower sıcak hava devri değerleri arttıkça filtre verimliliğine etkisi düzenli bir değişim göstermemiştir. MBTAS 1-3-7 ve MBTAS 12-15-18 deneme gruplarında blower sıcak hava devri arttıkça filttre verimliliği önce artış daha sonra düşüş göstermiştir. MBTAS 2-5-8 numune grubunda filtre performansı önce düşüş daha sonra artış göstermiştir. MBTAS 10-13-16 ve MBTAS 11-14-17 deneme gruplarında ise azalış görülmüştür. MBTAS 3-6-9 grubunda ise sürekli bir artış görülmüştür.

Belt-kalıp mesafesi $40 \quad \mathrm{~cm}$ 'den $50 \quad \mathrm{~cm}$ 'e yükseltildiğinde, filtre verimliliği değerleri öncelikle düşüş göstermiş daha sonrasında bir miktar iyileşme görülmüştür. Ancak en verimli belt-kalıp mesafesi değeri $40 \mathrm{~cm}$ olduğu Şekil 6'da verilen grafikten anlaşılmaktadır.

\section{Sonuç ve öneriler}

Meltblown kumaşlar, sorbent sektöründe emicilik özelliği ile filtre sektöründe toz tutuculuk yeteneği ve hava geçirgenliği ile kompozit ve diğer sektörlerde mukavemet, gramaj ve kalınlık gibi fiziksel özellikleri ön plana çıkmaktadır. Çalışmada meltblown kumaşların, fiziksel özellikleri üzerinde blower sıcak hava devri (1750 rpm, $1800 \mathrm{rpm}$ ve $1850 \mathrm{rpm}$ ) ve belt-kalıp mesafesi $(40 \mathrm{~cm}, 45 \mathrm{~cm}$ ve $50 \mathrm{~cm}$ ) değişkenlerinin etkileri incelenmeye çalışılmıştır. Sadece bir değişkenin tek başına meltblown kumaş fiziksel özelliklerine etkisinin kısıtlı bir iyileşme sağladığı görülmüştür. Örneğin kalıp-belt mesafesi değişkeni için MBTAS 1/2/3 numune grubunda filtre yeteneği 
yükseliş gösterirken, MBTAS 10/11/12 numune grubunda düşüş göstermiştir. Her iki grup arasında blower hava sıcaklığı farkının $10{ }^{\circ} \mathrm{C}$, polimer ergime sıcaklığının $5^{\circ} \mathrm{C}$ ve belt emiş fanının 100 rpm olmasıdır. Bu sebeple iyileştirilmeye çalışılan özellik için tek değişkende elde edilen başarı değişkenlerin sayısı arttıkça, negatif yönde sonuçlar doğurabilir. $\mathrm{Bu}$ sebeple meltblown kumaştan beklenti hangi fiziksel özelliğin iyileştirilmesine yönelik ise sadece bir veya ilişkili olduğu parametreyi iyileştirme çalışmaları yapılmalıdır. Aksi halde beklenmedik sonuçlar ile karşılaşılmaktadır. Yukarıdaki test sonuçlarına göre mukavemet, filtre ve yağ emiciliği ihtiyaç olan sektörlerde farklı kumaşlar yüksek performans göstermiştir. $\mathrm{Bu}$ değerler, ilgili sektörler için referans kabul edilebilir.

\section{Teşekkür}

$\mathrm{Bu}$ çalışma Teknomelt Arge Merkezi bünyesinde yürütülen çalışmanın çıktılarından faydalanıldığg için Teknomelt Teknik Mensucat San ve Tic. A.Ş. Arge Merkezine ve emek harcayan tüm Teknomelt çalışanlarına teşekkürü bir borç biliriz.

\section{Kaynaklar}

Albrecht, W., Fuchs, H. and Kittelmann, W. (2003). Nonwoven Fabrics: Raw Materials, Manufacture, Applications, Characteristics, Testing Process. Weinheim, Almanya: Wileyvch Verlag Gmbh \& Co. KGaA.

Aslan, S. ve Kaplan, S. (2010). Filtrasyon tekstilleri: kullanılan hammaddeler, üretim yöntemleri ve kullanım alanları. Tekstil ve Mühendis, 17(79), 24-37.

Bhat, G., Uppal, R. and Eash, C. (2009). Structure and properties of meltblown nanofiber webs [C]. The Fiber Society 2009 Fall Meeting and Technical Conference (p. 71). The Georgia Center Athens, Georgia, USA.

Bin, Y., Xuyang, Z., Jinjin, K. Feichao, Z., Bhat, G., Jian, H. and Peng, W., 2016. Influence of dietocollector distance on structure and property of the PLA meltblowing web. Rare Metal Materials and Engineering, 45, 345-349.

Demiröz Gün, A., Demircan, B. ve Şevkan, A. (2011). Mikroliflerin üretim yöntemleri, özellikleri ve kullanım alanları. Tekstil ve Mühendis, 18(83), 38-46.

Doğan, G. (2006). Kuru hava filtrasyonunda kullanılan dokusuz yüzeylerin performanslarl üzerine bir çalışma. Yüksek Lisans Tezi, Afyon Kocatepe Üniversitesi Fen Bilimleri Enstitüsü, Afyonkarahisar.
Dönmez, U., Sütsatar, A., Sevim, M. ve Akgül, D. (2019a). Meltblown üretim tekniğinde blower sıcaklık ve pompa devri değişkenlerinin kumaş mukavemetine etkisi. 3rd International Zeugma Conference on Scientific Researches (pp. 642 656). Gaziantep.

Dönmez, U., Fişne, M., Hayta Başkan, Z. ve Arpasatan, Z. (2019b). Blower sicaklik ve pompa devri parametrelerinin eriyik üfleme tekniği ile elde edilen dokusuz yüzey kumaşlarda yağ emicilik miktarına etkisi. 3rd International Zeugma Conference on Scientific Researches, (pp. 631 641). Gaziantep.

Duran, D. (2012). Investigation of the physical characteristics of polypropylene meltblown nonwovens under varying production parameters. Elastomeric Polymers, 12, 243-264.

Duran, D. and Duran, K. (2013). Meltblown nonwovens: effect of production parameters on physical properties. 14th National \& $1 s t$ International Textile Technology and Chemistry Symposium, Bursa, 8-10 May 2013.

Duran K., Duran D., Oymak G., Kılıç K., Öncü E. and Kara M. (2013). Investigation of the physical properties of meltblown nonwovens for air filtration. Tekstil ve Konfeksiyon, 23(2), 136-142.

Duran, D. and Perincek, S. (2010). The Effect of various production parameters on the physical properties of polypropylene meltblown nonwovens. Industria Textila, 61(3), 117-123.

Dutton, K.C. (2008). Overview and analysis of the meltblown process and parameters. Journal of Textile and Apparel, Technology and Management (JTATM). 6(1), 1-24.

Ellison C. J, Phatak A, Giles D. W., Macosko C. W. and Bates F. S. (2007). Melt blown nanofibers: fiber diameter distributions and onset of fiber breakup. Polymer 48, 3306-3316. https://doi:10.1016/j.polymer.2007.04.005

Hagewood, J. (2011, May1s 30). Spinning of submicron diameter fibers. www.hillsinc.net/spinningfiber.shtml.

Han, W., Wang, X. and Bhat, G. S. (2013). Structure and air permeability of melt blown nanofiber webs. Journal of Nanomaterials Molecular Nanotechnology, 2(3), 1-5.

Hassan, M. A., Yeom, B. Y., Wilkie, A., Pourdeyhimi, B. and Khan, S. A. (2013). Fabrication of nanofiber meltblown membranes and their filtration properties. Journal of Membrane Science, 427, 336-344. http://dx.doi.org/10.1016/j.memsci.2012.09.050 
Hegde R. R. and Bhat G. S. (2010). Nanoparticle effects on structure and properties of polypropylene meltblown webs. Journal of Applied Polymer Science 115, 1062-1072. https://doi.org/10.1002/app.31089

Horrocks, A. R. and Anand, S. C. (2000). Handbook of Technical Textiles. Cambridge, England: Woodhead Publishing Ltd.,

Hutten, I. M. (2007). Handbook of Nonwoven Filter Media. USA: Burlington.

Kaynak, K. H. ve Değirmenci, Z. (2010). Teknik tekstil uygulamalarında kullanılan nonwoven filtreler. Tekstil Teknolojileri Elektronik Dergisi, 4(2), 7884.

Lalagiri, M., Bhat, G., Singh, V., Parameswaran, S., Kendall, R.J. and Ramkumar, S. (2013). Filtration efficiency of submicrometer filters. Industrial \& Engineering Chemistry Research, 52(46), 16513-16518. https://doi.org/10.1021/ie403093t

Lee, B. O., Ko, J. A. and Han, S. W. (2010). Characteristics of PP/PET bicomponent melt blown nonwovens as sound absorbing material. In Advanced Materials Research, 123, 935-938. https://doi.org/10.4028/www.scientific.net/AM R.123-125.935

Mukhopadhyay, S. (2002). Microfibres-an overview. Indian Journal of Fibres \& Textile Research, 27, 307-314.

Mukhopadhyay, S. and Ramakrishnan, G. (2008). Microfibres, Textile Progress, 40, 1-86. https://doi.org/10.1080/00405160801942585

Russell S. J. (2007). Handbook of Nonwovens. (1st Edtn). Cambridge, England: CRC Press. Woodhead Publications.

Srinivas, S., Cheng, C. Y., Dharmarajan, N. ande Racine, G. (2005). Elastic nonwoven fabrics from polyolefin elastomers. Baytown, TX: ExxonMobil Chemical. Erişim adresi: https://www.semanticscholar.org/paper/ElasticNonwoven-Fabrics-from-PolyolefinElastomers-Srinivas-

Cheng/23e2c85a50d641ac7e56a4405e21a42e4d b7092a

Subbiah T., Bhat G. S., Tock R. W., Parameswaran S. and Ramkumar S. S. (2005). Electrospinning of nanofibers. Journal of Applied Polymer Science 96, 557-569. https://doi.org/10.1002/app.21481

Uppal R., Bhat G., Eash C. and Akato K. (2013). Meltblown nanofiber media for enhanced quality factor. Fibers and Polymers 14, 660-668. https://doi.org/10.1007/s12221-013-0660-Z

Ward G. F. (2001). Meltblown nanofibres for nonwoven filtration applications. Filtration \& Separation, $38(9), 42-43$.

Wei, Z. (2018). Research process of polymer nanofibers prepared by melt spinning. IOP Conference Series: Materials Science and Engineering 452(2), 022002.

Xiao, Y., Sakib, N., Yue, Z., Wang, Y., You, J., Militky, J., Venkataraman, M. and Zhu, G. (2019). Study on the relationship between structure parameters and filtration performance of polypropylene meltblown nonwovens. Autex Research Journal, 20(4), 366-371. https://doi.org/10.2478/aut2019-0029

Zhang, D., Sun, C., Beard, J., Brown, H., Carson, I. and Hwo, C. (2002). Development and characterization of poly (trimethylene terephthalate)-based bicomponent meltblown nonwovens. Journal of Applied Polymer Science, 83(6), 1280-1287. 